\title{
Minute Effects of Sex on the Aging Brain: A Multisample Magnetic Resonance Imaging Study of Healthy Aging and Alzheimer's Disease
}

\author{
Anders M. Fjell, ${ }^{1,3}$ Lars T. Westlye, ${ }^{1}$ Inge Amlien, ${ }^{1}$ Thomas Espeseth, ${ }^{1}$ Ivar Reinvang, ${ }^{1}$ Naftali Raz,,${ }^{4,5}$ Ingrid Agartz, ${ }^{2,6,7}$ \\ David H. Salat, ${ }^{8}$ Doug N. Greve, ${ }^{8}$ Bruce Fischl ${ }^{8,9}$ Anders M. Dale, ${ }^{10,11,12}$ and Kristine B. Walhovd ${ }^{1,3}$ \\ ${ }^{1}$ Center for the Study of Human Cognition, Department of Psychology, and ${ }^{2}$ Department of Psychiatry, University of Oslo, 0317 Oslo, Norway, ${ }^{3}$ Department \\ of Neuropsychology, Ullevaal University Hospital, Oslo 0317, Norway, ${ }^{4}$ Department of Psychology and 5 Institute of Gerontology, Wayne State University, \\ Detroit, Michigan 48202, ${ }^{6}$ Department of Psychiatric Research, Diakonhjemmet Hospital, 0319 Oslo, Norway, ${ }^{7}$ Human Brain Informatics, Department of \\ Clinical Neuroscience, Psychiatry Section, Karolinska Institutet and Hospital, 17176 Stockholm, Sweden, ${ }^{8}$ Athinoula A. Martinos Center, Department of \\ Radiology, Harvard Medical School/Massachusetts General Hospital, Charlestown, Massachusetts 02129, ${ }^{9}$ Massachusetts Institute of Technology Computer \\ Science and Artificial Intelligence Laboratory, Cambridge, Massachusetts 02139, and ${ }^{10}$ Multimodal Imaging Laboratory and Departments of ${ }^{11}$ Radiology \\ and ${ }^{12}$ Neurosciences, University of California, San Diego, La Jolla, California 92093
}

Age is associated with substantial macrostructural brain changes. While some recent magnetic resonance imaging studies have reported larger age effects in men than women, others find no sex differences. As brain morphometry is a potentially important tool in diagnosis and monitoring of age-related neurological diseases, e.g., Alzheimer's disease (AD), it is important to know whether sex influences brain aging. We analyzed cross-sectional magnetic resonance scans from 1143 healthy participants from seven subsamples provided by four independent research groups. In addition, 96 patients with mild AD were included. Estimates of cortical thickness continuously across the brain surface, as well as volume of 17 subcortical structures, were obtained by use of automated segmentation tools (FreeSurfer). In the healthy participants, no differences in aging slopes between women and men were found in any part of the cortex. Pallidum corrected for intracranial volume showed slightly higher age correlations for men. The analyses were repeated in each of the seven subsamples, and the lack of age $\times$ sex interactions was largely replicated. Analyses of the AD sample showed no interactions between sex and age for any brain region. We conclude that sex has negligible effects on the age slope of brain volumes both in healthy participants and in AD.

\section{Introduction}

More than 50 magnetic resonance imaging (MRI) studies of sex effects on brain structures have been published, partly motivated

Received Dec. 19, 2008; revised April 6, 2009; accepted April 29, 2009.

The present paper was funded by the following grants: the Norwegian Research Council (177404/W50 to K.B.W. 175066/D15 to A.M.F., 154313/V50 to I.R., and 177458/V50 to T.E.), the University of Oslo (to K.B.W. and A.M.F.), the National Institutes of Health (NIH) (R01-NS39581, R37-AG11230, and R01-RR13609), the Mental Illness and Neuroscience Discovery Institute, The Wallenberg Foundation and the Swedish Medical Research Council (2008-2167), the National Center for Research Resources (NCRR) (P41-RR14075, R01 RR16594-01A1, and NCRR Biomedical Informatics Research Network Morphometric Project Grants BIRN002 and U24 RR021382), the National Institute for Biomedical Imaging and Bioengineering (R01 EB001550 and R01EB006758), the National Institute for Neurologica Disorders and Stroke (R01 NS052585-01), and the National Alliance for Medical Image Computing, funded by the National Institutes of Health through the NIH Roadmap for Medical Research, Grant U54 EB005149. Additional support was provided by The Autism \& Dyslexia Project funded by the Ellison Medical Foundation. We thank the developers of the OASIS (Open Access Series of Imaging Studies) database for access to MRI data constituting samples 4 and 5 of the present work. According to Marcus et al. (2007), the OASIS database is supported by NIH Grants P50 AG05681, P01 AG03991, P20 MH071616, RR14075, RR 16594, and BIRN002, the Alzheimer's Association, the James S. McDonnell Foundation, the Mental IIIness and Neuroscience Discovery Institute, and the Howard Hughes Medical Institute.

A.M.D. is a founder of and holds equity in CorTechs Labs, Inc, and also serves on the Scientific Advisory Board. The terms of this arrangement have been reviewed and approved by the University of California, San Diego, in accordance with its conflict of interest policies.

Correspondence should be addressed to Anders M. Fjell, Department of Psychology, Pb. 1094 Blindern, 0317 0slo, Norway. E-mail:andersmf@psykologi.uio.no.

DOI:10.1523/JNEUROSCI.0115-09.2009

Copyright $\odot 2009$ Society for Neuroscience $\quad$ 0270-6474/09/298774-10\$15.00/0 by observations of small, but consistent, sex differences in cognitive abilities (Halpern and Tan, 2001; Jones et al., 2003). More importantly, as brain morphometry emerges as a valuable tool in prediction and diagnosis of age-related neurological disorders, e.g., Alzheimer's disease (AD) (Fischl et al., 2002; Dubois et al., 2007; Colliot et al., 2008), it is increasingly important to understand the factors that influence volumetric changes with increasing age. Although much is known about the general pattern of age effects on brain morphometry from cross-sectional studies (Courchesne et al., 2000; Jernigan et al., 2001; Raz et al., 2004b, 2007; Salat et al., 2004; Fotenos et al., 2005; Walhovd et al., 2005a,b; Fjell et al., 2009), the role of sex in brain aging is still controversial. Although extremely valuable longitudinal studies of aging exist (Resnick et al., 2003; Raz et al., 2004a), the age spans sampled are small, and the present paper will focus on crosssectional studies. Some studies have found more age-related regional volume differences in men than in women (Cowell et al., 1994; Murphy et al., 1996; Coffey et al., 1998; Resnick et al., 2000; Xu et al., 2000; Good et al., 2001; Pruessner et al., 2001; Gur et al., 2002a; Raz et al., 2004b; Riello et al., 2005; Chung et al., 2006; Sowell et al., 2007; Nunnemann et al., 2009), while others have found no sex differences (Salat et al., 2004; Lemaître et al., 2005; Sowell et al., 2007; Greenberg et al., 2008), or a heterogeneous 
Table 1. Sample characteristics

\begin{tabular}{|c|c|c|c|c|c|c|}
\hline Sample & Country & $n(\% \mathrm{f})$ & Age [mean (range)] & $\begin{array}{l}\text { Education } \\
\text { [mean (range) }]\end{array}$ & Key publications & Main screening instruments/inclusion criteria \\
\hline 1 & Nor & $69(57)$ & $51.3(20-88)$ & $15(7-20)$ & Walhovd et al. (2005a) & $\begin{array}{l}\text { Health interview, MMSE }>26, \mathrm{BDI}<16,10>85 \text {, } \\
\text { RH only }\end{array}$ \\
\hline 2 & Nor & $208(71)$ & $46.8(19-75)$ & $14(9-22)$ & Espeseth et al. (2008) & Health interview, IQ $>85$ \\
\hline 3 & Swe & $106(32)$ & $41.6(19-56)$ & $14(9-22)$ & Nesvåg et al. (2008) & Health interview, DSM-III-R, WASI vocabulary $>16^{a}$ \\
\hline 4 & USA & $155(65)$ & $44.5(18-93)$ & $3.5(1-5)^{b}$ & Marcus et al. (2007) & Health interview, $\mathrm{CDR}=0^{c}, \mathrm{MMSE}>25^{\circ}, \mathrm{RH}$ only \\
\hline 5 & USA & $154(61)$ & $44.4(18-94)$ & $3.4(1-5)^{b}$ & Similar to sample 4 & Similar to sample 4 \\
\hline 6 & USA & $191(60)$ & $47.3(18-81)$ & $15.7(12-21)$ & Raz et al. (2004b) & $\begin{array}{l}\text { Health interview, BIMCT }>30, \mathrm{GDQ}<15 \text {, RH only, } \\
\text { neuroradiology }\end{array}$ \\
\hline 7 & Nor & $260(57)$ & $48.8(20-93)$ & $15.5(8-23)^{d}$ & Fjell et al. (2008) & $\begin{array}{l}\text { Health interview, neuropsychological evaluation, BDI } \\
\quad<16, \mathrm{IQ}>85 \text {, RH only }\end{array}$ \\
\hline $8^{e}$ & USA & $96(59)$ & $76.6(62-96)$ & $2.8(1-5)^{b}$ & Similar to sample 4 & Health interview, $C D R \geq 0.5$, RH only \\
\hline
\end{tabular}

Nor, Norway; Swe, Sweden; \% f, percentage of female participants; MMSE, Mini Mental Status Exam (Folstein et al., 1975); BDI, Beck Depression Inventory (Beck, 1987); BIMCT, Blessed Information-Memory-Concentration Test (Blessed et al., 1968); (DR, Clinical Dementia Rating (Berg, 1984, 1988; Morris, 1993); GDQ, Geriatric Depression Questionnaire (Auer and Reisberg, 1997); RH, right handed; WASI, Wechsler Abbreviated Scale of Intelligence (Wechsler, 1999). ${ }^{a}$ Available for 70 participants.

${ }^{b}$ Available for all participants $\geq 60$ years, and sporadically for the rest. 1, Less than high school graduate (grad.); 2, high school grad.; 3, some college; 4, college grad.; 5, beyond college. 'Available for participants $\geq 60$ years only.

${ }^{d}$ Missing for one participant.

${ }^{e}$ Alzheimer patients.

pattern across different brain structures (Murphy et al., 1996; Gunning-Dixon et al., 1998; Pruessner et al., 2001; Gur et al., 2002a; Cowell et al., 2007). The inconsistencies may be caused by differences in sample characteristics, scan quality, segmentation approach, or statistical procedures. Limited attempts to replicate the pattern of sex difference in regional brain aging in samples drawn from the same population using the same equipment were unsuccessful (Raz et al., 1997, 2004b). We tested whether age affects the brains of women and men differentially by addressing these sources of variation. A total of 1143 healthy participants from seven cross-sectional life-span samples were included in the combined sample. In addition, $96 \mathrm{AD}$ patients were included in a separate sample. This made it possible to account for sample- and scan-related factors that could influence the results. We tested how sex influences the magnitude and direction of age effects on cortical thickness and the volumes of 17 different subcortical brain structures. No previous studies have tested effects of sex in healthy aging or $\mathrm{AD}$ on such a large number of subcortical and cortical structures simultaneously.

\section{Materials and Methods}

Samples. Age correlations across six of the seven healthy samples $(n=$ 883 ) have been reported previously (Fjell et al., 2009), without analyses of sex effects. The details of each of the subsamples are described in Table 1, as well as in a previous publication from the project (Fjell et al., 2009). The current sample consisted of 1143 participants (676 women, 467 men), with an age range of 76 years ( $18-94$ years, mean $=46.8, \mathrm{SD}=$ 19.2). All the healthy samples were well screened for diseases and history of neurological conditions, and for cognitive deficits/dementia by standardized tests. Ninety-six AD patients (59 women/37 men) were included from the Open Access Series of Imaging Studies (OASIS) database (www.oasis-brains.org), with an age range of 34 years (62-96 years, mean $=76.6, \mathrm{SD}=7.1)$. Details of recruitment and screening procedures for the AD group were given by Marcus et al. (2007). AD participants underwent the Washington University Alzheimer Disease Research Center's full clinical assessment, yielding Clinical Dementia Rating (CDR) (Berg, 1984, 1988; Morris, 1993; Morris et al., 2001). CDR of 0.5 or higher was taken to indicate mild or moderate AD.

MR acquisition. All scans were obtained from 1.5 T magnets from two different manufacturers [Siemens and General Electric (GE)], and from five different models (Siemens Avanto, Symphony, Sonata, and Vision and GE Signa). All participants within each sample were scanned on the same scanner. T1-weighted sequences were acquired [three-dimensional (3D) magnetization-prepared gradient echo for Siemens/3D spoiled gra- dient recalled pulse sequences for GE]. In five of the samples (samples 1 , $2,4,5$, and 7) multiple scans were acquired within the same scanning session and averaged to increase the signal-to-noise ratio. The details of the sequences are presented in Table 2.

MRI analysis. All datasets were processed and analyzed with FreeSurfer 4.01 (http://surfer.nmr.mgh.harvard.edu/) at the Neuroimaging Analysis Lab, Center for the Study of Human Cognition, University of Oslo, with the additional use of computing resources from the $\sim 4000$-central-processingunit Titan grid cluster (http://hpc.uio.no) run by the Research Computing Services Group at USIT (Universitetets senter for informasjonsteknologi), University of Oslo. The automated procedure for volumetric measures of the different brain structures is described in detail by Fischl et al. $(2002,2004)$. A label was automatically assigned to each voxel in the MRI volume based on probabilistic information automatically estimated from a manually labeled training set. The training set included both healthy persons in the age range $18-87$ years and a group of $\mathrm{AD}$ patients in the age range $60-87$ years, and the classification technique used a registration procedure that is robust to anatomical variability, including the ventricular enlargement typically associated with aging. The technique has been shown to be comparable in accuracy to manual labeling (Fischl et al., 2002, 2004). We also applied a newly developed atlas normalization procedure, which has been shown to increase the robustness and accuracy of the segmentations across scanner platforms (Han and Fischl, 2007). Two limitations must be mentioned: the segmentation labeled "CSF" in FreeSurfer represents CSF in an area superior to the brainstem, inferior to the fornix, and posterior to the third ventricle. An example of the segmentation is presented in supplemental Figure 1 (available at www.jneurosci.org as supplemental material). However, it is important to note that this is less validated than the other CSF measures (ventricles), and that strong conclusions should thus not be drawn regarding CSF based on this measure. The measure is included in the whole-brain segmentation (the FreeSurfer label "CSF"), and we therefore report results for it. Second, the cortical volume estimates from the whole-brain segmentation approach are probably less accurate than the surface-based thickness calculations. However, to ease comparison with the subcortical volumes, the whole-brain procedure was used for estimating all volume (but not thickness) data. Intracranial volume (ICV) was calculated by use of an atlas normalization procedure described by Buckner et al. (2004).

Cortical thickness was obtained by reconstructing representations of the gray/white matter boundary (Dale and Sereno, 1993; Dale et al., 1999) and the cortical surface, and the distance between these surfaces at each point across the cortical mantle was calculated. This method uses both intensity and continuity information from the entire 3D MR volume in segmentation and deformation procedures to construct representations of cortical thickness. The maps were created using spatial intensity gradients across tissue classes and are therefore not simply reliant on absolute signal intensity. The 


\begin{tabular}{|c|c|c|}
\hline Sample & MRI scanner & MRI protocol \\
\hline \multirow[t]{5}{*}{1} & \multirow[t]{5}{*}{ Siemens Symphony Quantum } & Two 3D MP-RAGE T1-weighted sequences \\
\hline & & $\mathrm{TR} / \mathrm{TE} / \mathrm{TI} / \mathrm{FA}=2730 \mathrm{~ms} / 4 \mathrm{~ms} / 1000 \mathrm{~ms} / 7^{\circ}$ \\
\hline & & Matrix $=192 \times 256$ \\
\hline & & Scan time: 8.5 min per volume \\
\hline & & Each volume consisted of 128 sagittal slices $(1.33 \times 1 \times 1 \mathrm{~mm})$ \\
\hline \multirow[t]{5}{*}{2} & \multirow[t]{5}{*}{ Siemens Sonata } & Two 3D MP-RAGE T1-weighted sequences \\
\hline & & $\mathrm{TR} / \mathrm{TE} / \mathrm{TI} / \mathrm{FA}=2730 \mathrm{~ms} / 3.43 \mathrm{~ms} / 1000 \mathrm{~ms} / 7^{\circ}$ \\
\hline & & Matrix: $256 \times 256$ \\
\hline & & Scan time: $8 \mathrm{~min}$ and $46 \mathrm{~s}$ per volume \\
\hline & & Each volume consisted of 128 sagittal slices $(1.33 \times 1 \times 1 \mathrm{~mm})$ \\
\hline \multirow[t]{4}{*}{3} & \multirow[t]{4}{*}{ General Electric Signa } & One 3D SPGR pulse T1-weighted sequence \\
\hline & & $\mathrm{TR} / \mathrm{TE} / \mathrm{FA}=24 \mathrm{~ms} / 6.0 \mathrm{~ms} / 35^{\circ}$, number of excitations was 2 \\
\hline & & Matrix: $256 \times 192$ \\
\hline & & Each volume consisted of $1.5 \mathrm{~mm}$ coronal slices, no gap, FOV $=24 \mathrm{~cm}$ \\
\hline \multirow[t]{4}{*}{4,5 , and 8} & \multirow[t]{4}{*}{ Siemens Vision } & 3-4 individual T1-weighted MP-RAGE sequences \\
\hline & & $\mathrm{TR} / \mathrm{TE} / \mathrm{T} \mathrm{I} / \mathrm{FA}=9.7 \mathrm{~ms} / 4.0 \mathrm{~ms} / 20 \mathrm{~ms} / 10^{\circ}$ \\
\hline & & Matrix $=256 \times 256$ \\
\hline & & Each volume consisted of 128 sagittal slices $(1.25 \times 1 \times 1 \mathrm{~mm})$. \\
\hline \multirow[t]{4}{*}{6} & \multirow[t]{4}{*}{ General Electric Signa } & One 3D SPGR pulse T1-weighted sequence \\
\hline & & $\mathrm{TR} / \mathrm{TE} / \mathrm{FA}=24 \mathrm{~ms} / 5.0 \mathrm{~ms} / 30^{\circ}$ \\
\hline & & Matrix $=256 \times 192$ \\
\hline & & Each volume consisted of 124 contiguous axial slices $(1.30 \times 0.94 \times 0.86 \mathrm{~mm}), F 0 V=22 \mathrm{~cm}$ \\
\hline \multirow[t]{5}{*}{7} & \multirow[t]{5}{*}{ Siemens Avanto } & Two 3D MP-RAGE T1-weighted sequences \\
\hline & & $\mathrm{TR} / \mathrm{TE} / \mathrm{TI} / \mathrm{FA}=2400 \mathrm{~ms} / 3.61 \mathrm{~ms} / 1000 \mathrm{~ms} / 8^{\circ}$ \\
\hline & & Matrix: $192 \times 192$ \\
\hline & & Scan time: $7 \mathrm{~min}$ and 42 s per volume \\
\hline & & Each volume consisted of 160 sagittal slices $(1.25 \times 1.25 \times 1.20 \mathrm{~mm})$ \\
\hline
\end{tabular}

FOV, Field of view; $\mathrm{FA}$, flip angle; TR, repetition time; TE, echo time; TI, inversion time; MP-RAGE, magnetization-prepared rapid gradient echo; SPGR, spoiled gradient recalled.

maps are not restricted to the voxel resolution of the original data and are thus capable of detecting submillimeter differences between groups (Fischl and Dale, 2000). This has been validated using MR and histology (Rosas et al., 2002; Kuperberg et al., 2003), and the results are not biased across scanner platforms (Han et al., 2006; Han and Fischl, 2007). Maps were smoothed using a circularly symmetric Gaussian kernel across the surface with a full width at half maximum of $15 \mathrm{~mm}$ and averaged across participants using a nonrigid high-dimensional spherical averaging method to align cortical folding patterns (Fischl et al., 1999b). This procedure provides accurate matching of morphologically homologous cortical locations among participants on the basis of each individual's anatomy while minimizing metric distortion, resulting in a measure of cortical thickness for each person at each point on the reconstructed surface. Statistical comparisons of surface maps were generated by computing a general linear model (GLM) of the effects of each variable on thickness at each vertex, which were mapped on the semiinflated surface of the average brain of the sample (Dale et al., 1999; Fischl et al., 1999a).

Statistics. Effect of sample was regressed out from all variables before statistical analysis. To test main effects of sex and sex $\times$ age interactions, GLMs were used, with brain structure (17 levels) as the within-subjects factor, and sex and age as between subjects factors. The analyses were done on uncorrected and ICV-corrected (residuals) volumes. ICV correction controls for sex differences in body size as well as in brain size at the earliest stages of development when ICV is affected by brain growth. In addition, group comparisons were done with corrections for total brain volume (TBV), adjusting the regional volumes for the differences in brain size, since previous studies have used this approach. This will not give a good approximation of age effects on the different structures, so these are not reported. TBV was quantified as the sum of all brain structures, not including CSF/ventricular system. The GLMs were followed by post hoc paired-samples $t$ tests, and correlated with age for each sex separately. Since Pearson coefficients are not symmetrically distributed around other values than 0 , the coefficients from the correlation analyses were $z$-transformed $(Z=1 / 2 \ln [1+r /(1-r)]$, where $\ln$ is the base- $e$ logarithm, $\mathrm{SD}=1 / \sqrt{n-3}$ ) and compared between women and men by $t$ tests. To test for nonlinear relationships, multiple regressions with age and age ${ }^{2}$ as simultaneous predictors were run for the ICV-corrected structures for women and men separately. Finally, GLMs were computed to test interactions between sex and age in the $\mathrm{AD}$ sample for the 17 volume estimates. Post hoc multiple regressions with age, sex, and age $\times$ sex were run, with cognitive status [CDR and Mini Mental Status Exam (MMSE) score] as additional predictors to control for possible gender differences in cognitive function.

\section{Results}

\section{Subcortical analyses}

For the 13 uncorrected hemispheric brain volumes [cerebral cortex, cerebral white matter (WM), hippocampus, amygdala, putamen, caudate, pallidum, accumbens, thalamus, lateral ventricles, inferior lateral ventricles, cerebellum cortex, and cerebellum WM], ANCOVA with hemisphere $\times$ sex $\times$ structure (13 volumes) with age and sample as covariates established that sex and hemisphere did not interact $\left(F_{(1,1139)}=0.001, p=0.973\right)$. Thus, the sum of left and right hemisphere was used in the rest of the analyses. The effect of sex on the volume of the different brain structures are shown in Figure 1. A GLM with 17 uncorrected volumes, sex, and age was run. Significant effects of sex $\left(F_{(1,998)}=290.99, p<10^{-56}\right)$ and age $\left(F_{(75,998)}=\right.$ 4.65, $\left.p<10^{-29}\right)$ were found, in addition to structure $\times$ sex $\left(F_{(8.28,8263.38)}=8.60, p<10^{-11}\right)$, structure $\times$ age $\left(F_{(621.00,8263.38)}=\right.$ $8.58, p=0.000)$, and structure $\times \operatorname{sex} \times$ age $\left(F_{(563.04,8263.38)}=1.30\right.$, $\left.p<10^{-5}\right)$ interactions. However, sex and age did not interact significantly $\left(F_{(68,998)}=1.214, p=0.119\right)$. Post hoc $t$ tests for each structure are presented in Table 3. Men had significantly larger volume than women for all structures. The largest differences were found for cerebral WM and cortex, cerebellum cortex, amygdala, and thalamus, in addition to TBV.

Correlations between age and structure, split by sex, are presented in Table 4. The difference in coefficient strength was assessed by $t$ tests of Fisher's $z$-transformed coefficients. Only for CSF did the age correlations differ significantly between the sexes ( 0.31 vs 0.49 for women and men, respectively). Scatter plots are 


\section{No volumetric corrections}

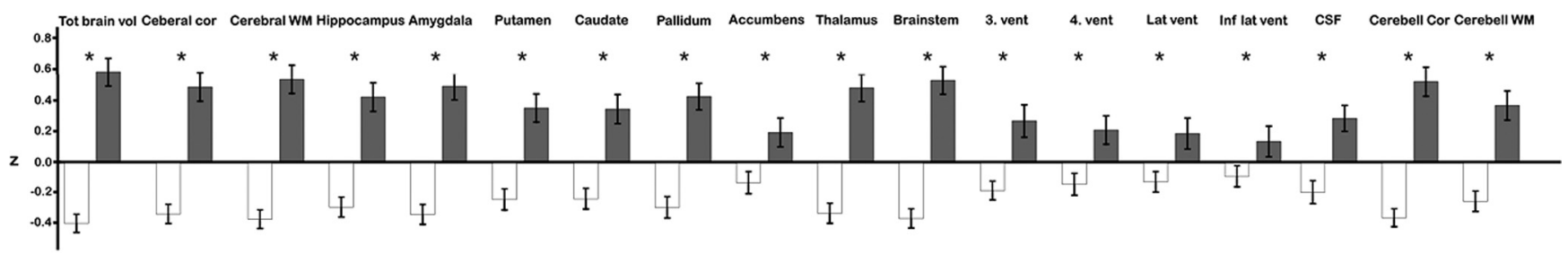

ICV corrected volumes

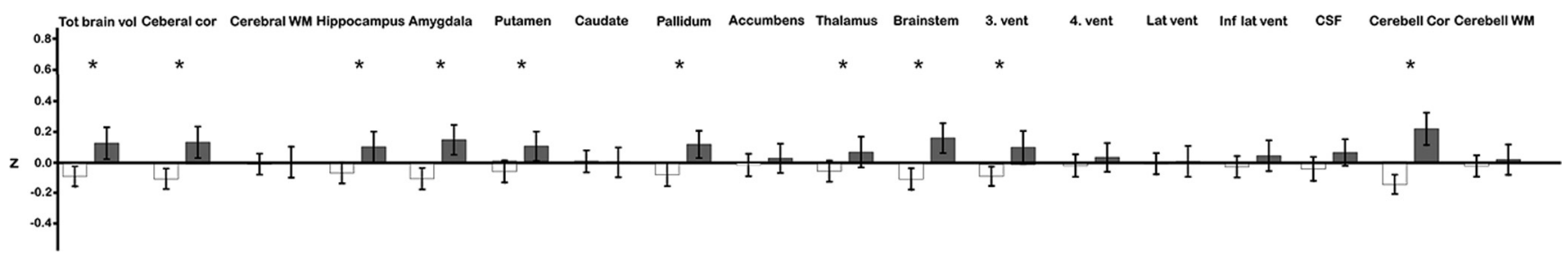

Figure 1. Volumetric differences between women and men. The bars illustrate the mean volume for women (red) and men (blue) separately for each of the brain volumes tested. The $95 \%$ confidence intervals are indicated. In the upper row, volumes are corrected for the effects of sample by means of regression analyses, and the standardized residuals are shown. In the middle row, the volumes are corrected for ICV in addition to sample, and in the final row they are corrected for total brain volume and sample. Men had significantly larger uncorrected volumes for all structures, and for several ICV-corrected structures, although the differences were much smaller in the latter cases. ${ }^{*} p<0.05$.

Table 3. Volume differences between women and men

\begin{tabular}{|c|c|c|c|c|c|c|}
\hline \multirow[b]{2}{*}{ Structure } & \multicolumn{2}{|c|}{ Corrected for sample } & \multicolumn{2}{|c|}{ Corrected for sample and ICV } & \multicolumn{2}{|c|}{ Corrected for sample and TBV } \\
\hline & Difference (z) & $t(p)$ & Difference (z) & $t(p)$ & Difference (z) & $t(p)$ \\
\hline 3rd ventricle & -0.455 & $-7.761\left(<10^{-13}\right)$ & -0.189 & $-3.154(<0.01)$ & -0.703 & $-12.458\left(<10^{-32}\right)$ \\
\hline 4th ventricle & -0.354 & $-5.978\left(<10^{-08}\right)$ & -0.054 & $-0.893\left(>0.05^{\text {n.s. }}\right)$ & -0.271 & $-4.540\left(<10^{-06}\right)$ \\
\hline Accumbens & -0.327 & $-5.506\left(<10^{-07}\right)$ & -0.043 & $-0.722\left(>0.05^{\text {n.s. }}\right)$ & 0.131 & $2.190(<0.05)$ \\
\hline Amygdala & -0.838 & $-15.283\left(<10^{-47}\right)$ & -0.253 & $-4.247\left(<10^{-03}\right)$ & -0.083 & $-1.377\left(>0.05^{\text {n.s. }}\right)$ \\
\hline Brainstem & -0.902 & $-16.731\left(<10^{-55}\right)$ & -0.268 & $-4.490\left(<10^{-04}\right)$ & -0.294 & $-4.948\left(<10^{-6}\right)$ \\
\hline Caudate & -0.586 & $-10.164\left(<10^{-22}\right)$ & 0.007 & $0.121\left(>0.05^{\text {n.s. }}\right)$ & -0.034 & $-0.561\left(>0.05^{\text {n.s. }}\right)$ \\
\hline Cerebellum cortex & -0.889 & $-16.432\left(<10^{-53}\right)$ & -0.363 & $-6.143\left(<10^{-07}\right)$ & -0.169 & $-2.824(<0.005)$ \\
\hline Cerebellum WM & -0.626 & $-10.938\left(<10^{-25}\right)$ & -0.041 & $-0.682\left(>0.05^{\text {n.s. }}\right)$ & -0.014 & $-0.225\left(>0.05^{\text {n.s. }}\right)$ \\
\hline Cerebral cortex & -0.830 & $-15.114\left(<10^{-46}\right)$ & -0.238 & $-3.988\left(<10^{-03}\right)$ & 0.159 & $2.658(<0.01)$ \\
\hline Cerebral WM & -0.914 & $-17.009\left(<10^{-57}\right)$ & -0.013 & $-0.222\left(>0.05^{\text {n.s. }}\right)$ & -0.093 & $-1.556\left(>0.05^{\text {n.s. }}\right)$ \\
\hline CSF & -0.483 & $-8.264\left(<10^{-15}\right)$ & -0.107 & $-1.781\left(>0.05^{\text {n.s. }}\right)$ & -0.472 & $-8.067\left(<10^{-14}\right)$ \\
\hline Hippocampus & -0.719 & $-12.785\left(<10^{-34}\right)$ & -0.169 & $-2.821(<0.005)$ & 0.125 & $2.088(<0.05)$ \\
\hline Inferior lateral ventricle & -0.228 & $-3.808\left(<10^{-02}\right)$ & -0.072 & $-1.194\left(>0.05^{\text {n.s. }}\right)$ & -0.565 & $-9.785\left(<10^{-21}\right)$ \\
\hline Lateral ventricle & -0.315 & $-5.306\left(<10^{-06}\right)$ & -0.016 & $-0.259\left(>0.05^{\text {n.s. }}\right)$ & -0.559 & $-9.665\left(<10^{-20}\right)$ \\
\hline Pallidum & -0.724 & $-12.872\left(<10^{-34}\right)$ & -0.197 & $-3.292(<0.005)$ & -0.123 & $-2.046(<0.05)$ \\
\hline Putamen & -0.597 & $-10.386\left(<10^{-23}\right)$ & -0.166 & $-2.765(<0.01)$ & 0.040 & $0.666\left(>0.05^{\text {n.s. }}\right)$ \\
\hline Thalamus & -0.820 & $-14.904\left(<10^{-45}\right)$ & -0.124 & $-2.065(<0.05)$ & 0.055 & $0.922\left(>0.05^{\text {n.s. }}\right)$ \\
\hline Total brain volume & -0.988 & $-18.798\left(<10^{-68}\right)$ & -0.216 & $-3.615(<0.001)$ & NA & NA \\
\hline
\end{tabular}

$t$ test of mean differences in volume are presented for the various brain structures included in the present paper. Results are shown for analyses done on the residuals after the effect of sample is regressed out, when the effects of sample and ICV are regressed out, and finally when the effects of sample and total brain volume are regressed out. Negative difference score and $t$ value indicate larger volume for men and positive indicate larger for women. Men had significantly larger uncorrected volumes for all structures and significantly larger ICV-corrected volumes for 10 structures. n.s., Not significant; NA, not applicable.

presented in Figures 2 (cerebrum cortex and WM), 3 (subcortical structures), and 4 (CSF compartments). To test whether the lack of sex $X$ age interactions was caused by reduced sensitivity due to merging of different subsamples, the GLM was rerun in each of the seven samples separately. For sample $2\left(F_{(28,128)}=2.33, p<\right.$ $0.001)$ and sample $7\left(F_{(36,159)}=1.96, p<0.05\right)$, significant age $\times$ sex interactions were found, while this was not seen in the other five samples ( $p$ ranging from 0.21 to 1.00 ). In sample 2 , CSF correlated significantly differently with age between the sexes ( $r=0.25$ vs 0.51 in women and men, respectively, $z=1.98, p<$ $0.05)$. In sample 7 , cerebellum cortex correlated significantly differently $(r=-0.45$ vs -0.63 in women and men, respectively, $z=2.03, p<0.05)$.

The analyses were repeated with ICV-corrected volumes. Main effects of sex $\left(F_{(1,998)}=14.22, p<0.001\right)$ and age $\left(F_{(75,998)}=6.59, p<10^{-47}\right)$ were confirmed. In addition, signif- icant structure $\times \operatorname{sex}\left(F_{(8.20,8187.37)}=3.82, p<0.001\right)$, structure $X$ age $\left(F_{(615.28,8187.37)}=7.97, p<0.000\right)$, and structure $X$ sex $\times$ age $\left(F_{(557.86,8187.37)}=1.33, p<10^{-6}\right)$ interactions were found. Age and sex did not interact $\left(F_{(68,998)}=0.90, p=0.71\right) . t$ tests showed significantly larger volumes for the third ventricle, amygdala, brainstem, cerebellum cortex, cerebral cortex, hippocampus, pallidum, putamen, and thalamus, in addition to TBV, for men (Table 3). Significant differences in age correlations were observed only for CSF ( 0.36 vs 0.59 for women and men, respectively) and pallidum ( -0.49 vs -0.58$)$ (Table 4$)$. The GLM was rerun in each of the seven samples separately, with no significant age $\times$ sex interactions ( $p$ values from 0.22 to 0.85 ) . The ANOVA for the total sample was repeated for the participants over 60 years of age, to test whether age $\times$ sex interactions could be found in this age span. There were still no significant age $\times$ sex interaction $\left(F_{(25,247)}=0.65, p=0.90\right)$. The residual 
Table 4. Age correlations for women and men

\begin{tabular}{|c|c|c|c|c|c|c|}
\hline \multirow[b]{2}{*}{ Structure } & \multicolumn{3}{|c|}{ Corrected for sample } & \multicolumn{3}{|c|}{ Corrected for sample and ICV } \\
\hline & Women & Men & $\operatorname{Diff}(z)$ & Women & Men & $\operatorname{Diff}(z)$ \\
\hline 3rd ventricle & 0.55 & 0.61 & 1.50 & 0.59 & 0.63 & 1.05 \\
\hline 4th ventricle & 0.11 & 0.08 & 0.50 & 0.15 & 0.10 & 0.84 \\
\hline Accumbens & -0.62 & -0.61 & 0.27 & -0.60 & -0.61 & 0.26 \\
\hline Amygdala & -0.58 & -0.51 & 1.65 & -0.55 & -0.52 & 0.70 \\
\hline Brainstem & -0.19 & -0.15 & 0.68 & -0.10 & -0.12 & 0.34 \\
\hline Caudate & -0.32 & -0.33 & 0.19 & -0.26 & -0.35 & 1.65 \\
\hline Cerebellum cortex & -0.53 & -0.53 & 0.00 & -0.48 & -0.53 & 1.11 \\
\hline Cerebellum WM & -0.38 & -0.33 & 0.95 & -0.33 & -0.34 & 0.19 \\
\hline Cerebral cortex & -0.69 & -0.66 & 0.91 & -0.67 & -0.69 & 0.62 \\
\hline Cerebral WM & -0.34 & -0.25 & 1.64 & -0.31 & -0.30 & 0.18 \\
\hline CSF & 0.31 & 0.46 & 2.93 & 0.36 & 0.50 & 2.86 \\
\hline Hippocampus & -0.53 & -0.49 & 0.90 & -0.50 & -0.49 & 0.22 \\
\hline Inferior lateral ventricle & 0.51 & 0.58 & 1.65 & 0.53 & 0.60 & 1.71 \\
\hline Lateral ventricle & 0.58 & 0.59 & 0.25 & 0.63 & 0.62 & 0.27 \\
\hline Pallidum & -0.54 & -0.56 & 0.48 & -0.49 & -0.58 & 2.09 \\
\hline Putamen & -0.71 & -0.68 & 0.96 & -0.68 & -0.68 & 0.00 \\
\hline Thalamus & -0.60 & -0.57 & 0.76 & -0.62 & -0.61 & 0.27 \\
\hline Total brain volume & -0.62 & -0.55 & 1.77 & -0.67 & -0.66 & 0.30 \\
\hline
\end{tabular}

Pearson correlations between age and the various neuroanatomical structures are presented for women and men separately. $t$ test of Fisher's $z$-transformed coefficients were done, and the $z$-scores for the pairwise contrasts as well as the significance levels are presented. Results are shown for analyses done on the residuals after the effect of sample is regressed out, and when the effects of sample and ICV are regressed out. The only difference was found for CSF, where the correlations for men were significantly higher than for women. Bold indicates $p<0.01$ for the difference between the coefficients; italic indicates $p<0.05$ for the difference between the coefficients. Diff, Difference.

variance for each variable was calculated for each sex separately. An ANOVA showed that the residual variance was highly and positively related to age $\left(F_{(75,998)}=135.91, p<0.0001\right)$, but no age $X$ sex interaction was seen $\left(F_{(68,998)}=\right.$ 1.22, $p=0.12$ ).

GLM with TBV-corrected volumes confirmed main effects of $\operatorname{sex}\left(F_{(1,998)}=53.344\right.$, $\left.p<10^{-12}\right)$. $t$ tests showed significantly larger TBV-corrected volumes for women for cerebral cortex and accumbens area, while larger volumes for men were found for the ventricular system (third ventricle, fourth ventricle, lateral and inferior lateral ventricles, and CSF), brainstem, cerebellum cortex, and pallidum (Table 3 ).

Effects of introducing a quadratic term were investigated for the ICV-corrected volumes (Table 5). A nonlinear fit yielded significantly more explained variance for both women and men for most structures. For pallidum, age ${ }^{2}$ did not increase amount of explained variance for either of the groups. For cerebral cortex, adding age $^{2}$ as a predictor increased the amount of explained variance from 45 to $48 \%$ ( $p<$ $10^{-6}$ ) in women, while the amount of explained variance did not increase significantly for men. The effect of age on cortical volume in women was decreasing with advancing age. For amygdala and cerebellum cortex, increasing effect of age in higher age was seen for men only. Generally, however, the amount of variance explained by age was very similar for men and women, as is illustrated in Figure 5. CSF and pallidum seemed to be more related to age in men than in women, and when the nonlinear component was added, cerebral white matter also seemed to be more related to age in the sample of men than in the sample of women.
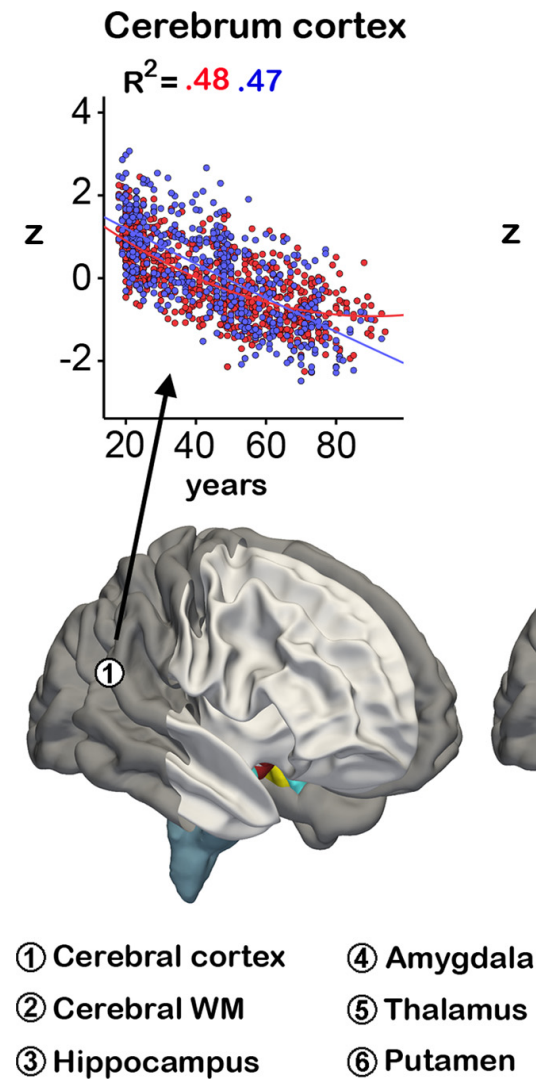

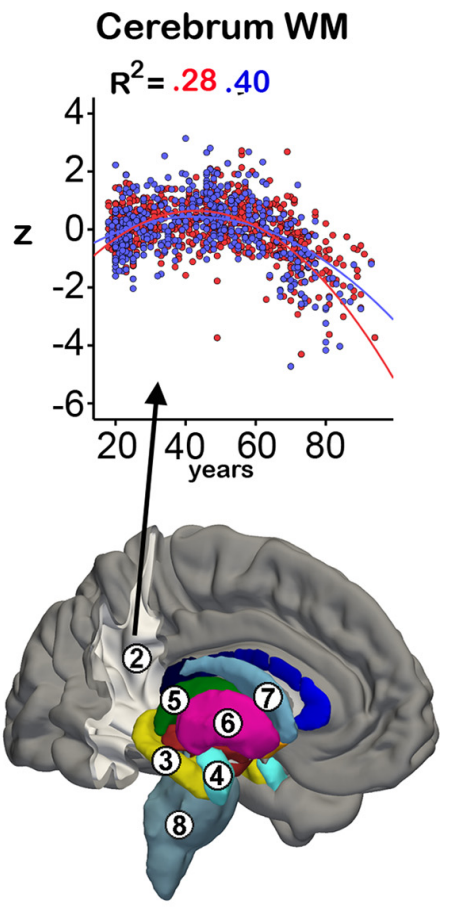

(7) Caudate

(8) Brainstem
Figure 2. Scatter plots of age effects on cerebrum. The scatter plots show the individual data points and the aging pattern for women (red) and men (blue) for cerebral cortex and white matter after ICV corrections of the volumes (the $y$-axes denote $z$-scores of the residuals). The numbers above each plot are the $R^{2}$ for women (red) and men (blue), respectively, including the contributions from both linear and nonlinear terms. In addition, the three-dimensional renderings of several of the structures included in the present paper are shown above the plots, based on the average brain of $\sim 70$ participants below 40 years.

\section{Cortical analyses}

GLMs were run to test for sex differences in cortical thickness and effects of aging (see Fig. 6). When age was regressed out, only minute and scattered effects of sex were seen, going in both directions (yellow-red: women thicker, blue-green: men thicker). When a 


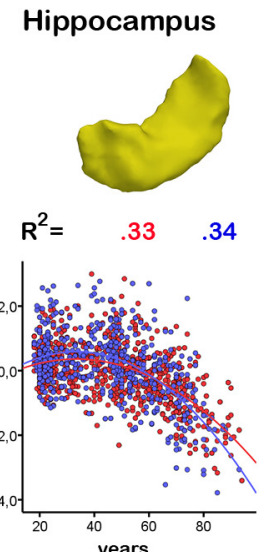

Pallidum

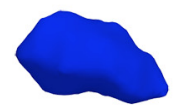

$\mathrm{R}^{2}=\quad .48 \quad .34$

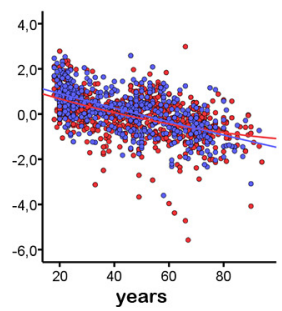

Caudate
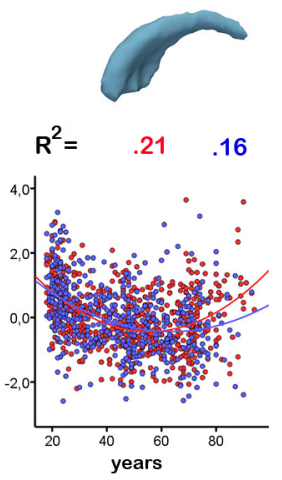

Putamen
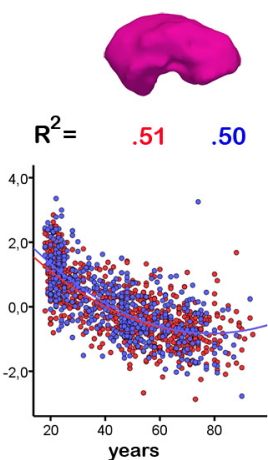

Thalamus
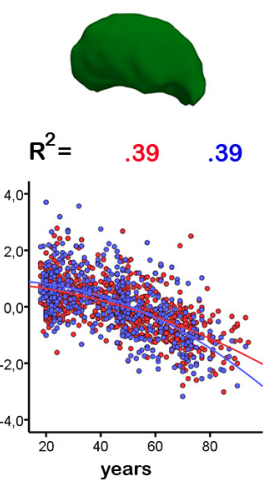

Cerebellum Cortex
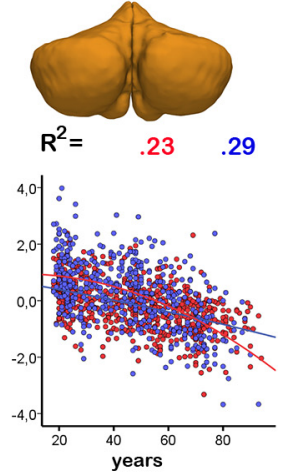

- Women Men
Accumbens
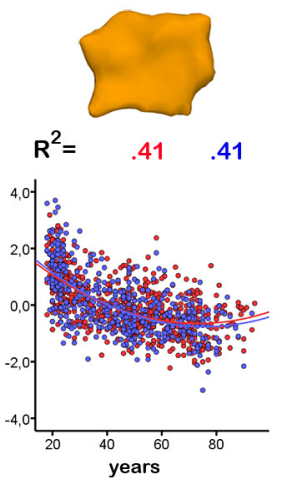

Cerebellum WM
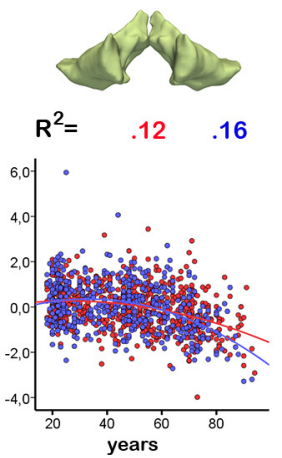

Amygdala
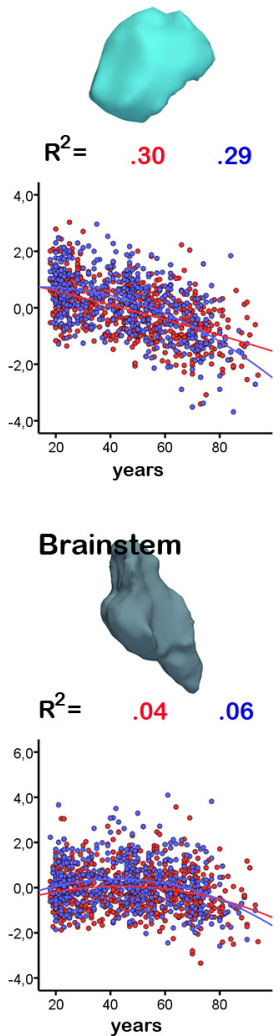

Figure 3. Scatter plots of age effects on subcortical structures. The scatter plots show the individual data points and the aging pattern for women (red) and men (blue) for selected subcortical structures after ICV corrections of the volumes (the $y$-axes denote $z$-scores of the residuals). The numbers above each plot are the $R^{2}$ for women (red) and men (blue), respectively, including the contributions from both the linear and the nonlinear terms. Above the plots, the three-dimensional renderings of the structures are shown, based on the average brains of $\sim 70$ participants below 40 years. Note that these are rescaled for the figure, and so their size cannot be visually compared. The age effects did not differ between women and men.
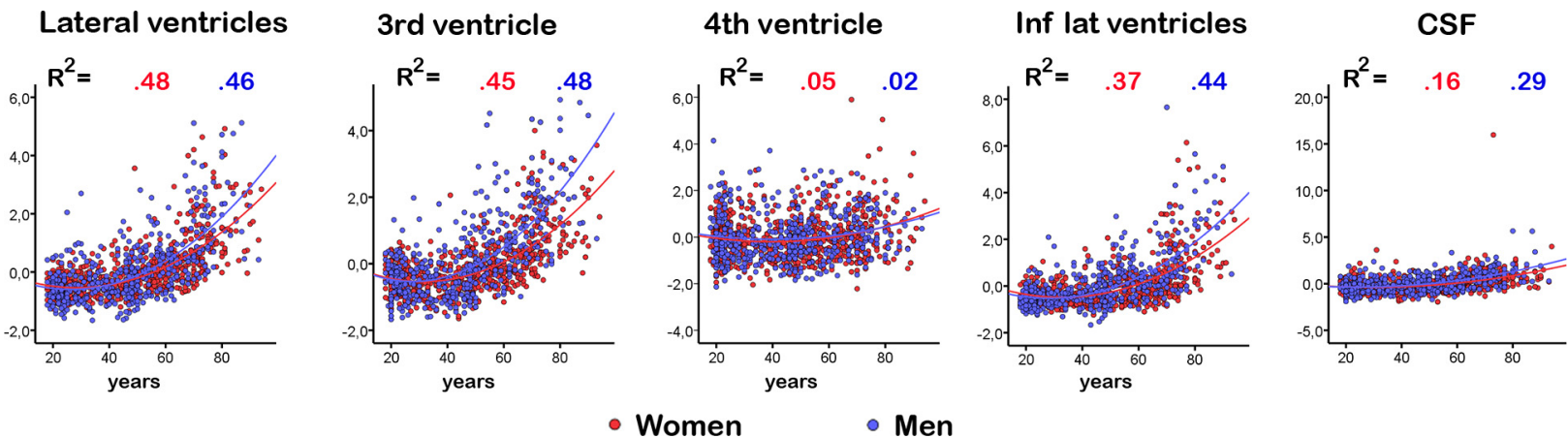

Figure 4. Scatter plots of aging patterns on CSF compartments. The scatter plots show the individual data points and the aging pattern for women (red) and men (blue) for the measured CSF compartments after ICV corrections of the volumes (the $y$-axes denote $z$-scores of the residuals). The numbers above each plot are the $R^{2}$ for women (red) and men (blue), respectively, including the contributions from both the linear and the nonlinear terms. CSF differed in age slope between women and men.

commonly used criterion for correction for multiple comparisons were used [false discovery rate $(\mathrm{FDR})<0.05$ ], no effects survived. The same was found when comparing the effects of age between women and men. Some scattered areas of steeper age slope in women than men (yellow-red) were seen, but did not survive correction for FDR. To test whether lack of effects could be due to merging of data from different samples, sex $X$ age interactions were tested for each of the seven samples independently. No effects survived the FDR $<0.05$ criterion for any of the samples.
Alzheimer's disease

ANCOVA with sex, age, and 17 uncorrected neuroanatomical volumes, and MMSE and CDR as covariates, yielded an effect of sex $\left(F_{(1,47)}=35.54, p=10^{-6}\right.$, men larger $)$, but no age $\times$ sex interaction $\left(F_{(17,47)}=1.58, p=0.11\right)$. For ICV-corrected volumes, trends were observed for $\operatorname{sex}\left(F_{(1,47)}=3.90, p=0.054\right)$, age $\left(F_{(28,47)}=1.53, p=0.10\right)$, and sex $\times$ age $\left(F_{(17,47)}=1.73, p=\right.$ $0.07)$. Finally, analysis of TBV-corrected volumes yielded no significant results (all $p$ values $>0.59$ ). Post hoc multiple regression 
Table 5. $R^{2}$ from multiple regressions with age and age ${ }^{2}$ as predictors

\begin{tabular}{lll}
\hline & \multicolumn{2}{l}{ Corrected for sample and ICV } \\
\cline { 2 - 3 } Structure & Women & Men \\
\hline 3rd ventricle & $\mathbf{0 . 4 5}$ & $\mathbf{0 . 4 8}$ \\
4th ventricle & $\mathbf{0 . 0 5}$ & $\mathbf{0 . 0 2}$ \\
Accumbens & $\mathbf{0 . 4 1}$ & $\mathbf{0 . 4 1}$ \\
Amygdala & 0.30 & $\mathbf{0 . 2 9}$ \\
Brainstem & $\mathbf{0 . 0 4}$ & $\mathbf{0 . 0 6}$ \\
Caudate & $\mathbf{0 . 2 1}$ & $\mathbf{0 . 1 6}$ \\
Cerebellum cortex & 0.23 & $\mathbf{0 . 2 9}$ \\
Cerebellum WM & $\mathbf{0 . 1 2}$ & $\mathbf{0 . 1 6}$ \\
Cerebral cortex & $\mathbf{0 . 4 8}$ & 0.47 \\
Cerebral WM & $\mathbf{0 . 2 8}$ & $\mathbf{0 . 4 0}$ \\
CSF & $\mathbf{0 . 1 6}$ & $\mathbf{0 . 2 9}$ \\
Hippocampus & $\mathbf{0 . 3 3}$ & $\mathbf{0 . 3 4}$ \\
Inferior lateral ventricle & $\mathbf{0 . 3 7}$ & $\mathbf{0 . 4 4}$ \\
Lateral ventricle & $\mathbf{0 . 4 8}$ & $\mathbf{0 . 4 6}$ \\
Pallidum & 0.24 & 0.34 \\
Putamen & $\mathbf{0 . 5 1}$ & $\mathbf{0 . 5 0}$ \\
Thalamus & $\mathbf{0 . 3 9}$ & $\mathbf{0 . 3 9}$ \\
Total brain volume & $\mathbf{0 . 4 6}$ & $\mathbf{0 . 5 0}$ \\
\hline
\end{tabular}

All structures were significantly related to age for both women and men. Bold indicates that the contribution from age $^{2}$ significantly $(p<0.05)$ increased the amount of explained variance.

analyses were run, with each of the 17 structures as dependent variables in turn, and CDR, MMSE, age, sex, and age $\times$ sex interaction as predictors. No sex $\times$ age interactions were significant.

\section{Discussion}

The results from the present large-scale multisample study indicate that sex exerts minute and unstable effects on age differences in brain morphometry, both in healthy aging and in AD. Sex did not influence the age slopes of regional cortical thickness, while there was a small effect of sex on the age slope of CSF and pallidum in healthy controls when corrected for ICV. Sex and age interacted in predicting brain morphometry uncorrected for ICV in two subsamples, but the effects were not replicable across other subsamples. This fits with the inconsistency of effects seen in previous research. Some find larger age slopes for men for at least some structures (Cowell et al., 1994; Murphy et al., 1996; Coffey et al., 1998; Resnick et al., 2000; Xu et al., 2000; Good et al., 2001; Pruessner et al., 2001; Gur et al., 2002a; Raz et al., 2004b; Riello et al., 2005; Chung et al., 2006; Sowell et al., 2007; Nunnemann et al., 2009), while others do not observe differences (Salat et al., 2004; Lemaître et al., 2005; Sowell et al., 2007; Greenberg et al., 2008). The large number of analyses conducted across multiple samples and brain regions increased the susceptibility to type I errors. This may have contributed to the between-samples inconsistency seen for the uncorrected volumes, i.e., the significant age $\times$ sex interactions found for samples 2 and 7 . While the effect in sample 2 would have survived a Bonferroni correction with a factor of almost 50, the effect in sample 7 would not survive any correction for multiple comparisons, even though the $n$ was as high as 260 .

The sex differences in age slope for CSF could indicate nonspecific sex effects on global atrophic processes. However, the age slopes for ICV-corrected total brain volumes were almost identical between the sexes $(-0.67$ vs -0.66 for females and males, respectively), which may speak against this interpretation. Further, as noted above, the CSF measure captures only a proportion of the total CSF, is less well validated than the other CSF measures, and should be interpreted with caution. It should also be stressed that the present data are cross-sectional, and thus can only address the issue of age differences, not aging per se. How- ever, it interesting that a longitudinal study did not find different rates of volumetric change for women and men over 4 years (Resnick et al., 2003).

With its 1143 healthy adults and $96 \mathrm{AD}$ patients, the present study is among the largest MR studies to date. Of the $44 \mathrm{MR}$ studies testing effects of sex on brain morphometry reported in the present paper, the median $n$ was 116 , while the median $n$ for the 29 who tested for sex differences in aging was 140 . Coupled with the use of validated, automated segmentation techniques, covering the entire brain, the present results could provide a firm basis for conclusion. Still, the most unique aspect of the present data is that separate analyses could be done in eight different samples, confirming the conclusions from the total sample.

As argued in the introduction, the discrepant results in previous literature can be caused by one or more of four different factors: (1) sample characteristics, (2) scan quality, (3) segmentation approach, or the (4) statistical procedures used. (1-2) To examine the influence of sample characteristics and scan quality, seven healthy subsamples were used, from six different scanners, four different research groups, and three different countries. If differences in sample characteristics and/or scan quality are responsible for the discrepancies in previous literature, it is likely that this would have been reflected across the subsamples included in the present study. Some inconsistencies across samples were found, but different age slopes for men and women were generally not seen. Differences in sample characteristics/scan quality may have contributed to the observed inconsistencies in previous literature, but did not appear to have a major impact on the results in the present study. (3) Further, the normalization procedure for head size had small but notable effects on the sex $X$ age interactions. The significance of the interaction term changed for some samples when the volumes were ICV corrected, indicating that different procedures can explain some of the discrepancies in previous literature. (4) Finally, it is possible that the segmentation procedure used may affect the degree to which sex differences are observed. It is interesting to note that the present results are in accordance with findings from the first surface-based study that mapped sex differences in thickness across the brain surface, in which age $\times$ sex interactions were largely not found (Sowell et al., 2007). Surface-based methods are likely to improve anatomical correspondence between the participants, which may enhance sensitivity to group differences. Further, the cortical analysis used in the present study is not restricted to anatomically defined areas. This stands in contrast to many volumetric studies, and increases the likelihood of detecting unexpected group differences. Finally, the methods applied in the present paper have been validated using both histological and manual methods (Fischl et al., 2002, 2004; Rosas et al., 2002; Kuperberg et al., 2003), and have been shown to be sensitive to various morphometric effects, e.g., of schizophrenia (Kuperberg et al., 2003; Nesvåg et al., 2008), mild cognitive impairment and AD (Du et al., 2007; Fjell et al., 2008), and prenatal opiate exposure (Walhovd et al., 2007). Further, the present results show high correlations between brain volumes and age, and replicated the established finding of larger raw volumes in men.

\section{Effects of sex on cortical thickness and brain volumes}

Sex differences in cortical thickness were not found. Sowell et al. (2007) found thicker cortex in women than men in posterior temporal and inferior parietal regions, independently of differences in brain or body size. They studied a relatively large sample (176 participants), and $p$ values of the three regions that differed 
Raw volumes

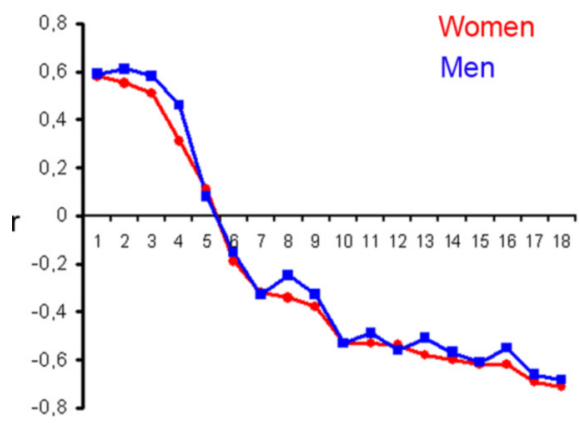

ICV corrected

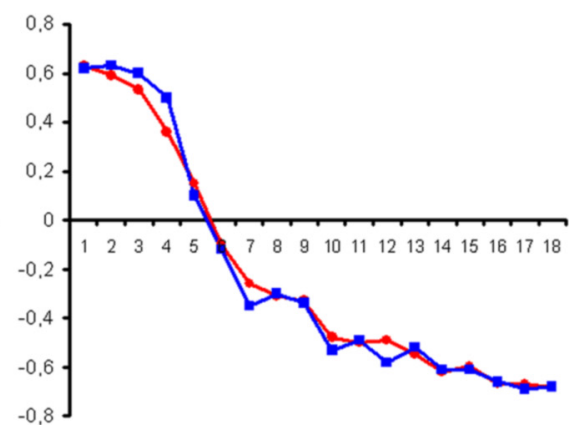

Figure 5. Correlations with age in women and men. The lines illustrate the Pearson correlations between volume and age for women (red) and men (blue). The values are sorted by the coefficient strength for the raw volumes in women. With the exception of CSF, where men showed higher correlations, none differed significantly between women and men. 1, Lateral ventricles; 2 , third ventricle; 3 , inferior lateral ventricles; 4 , CSF; 5 , fourth ventricle; 6 , brainstem; 7, cerebral WM; 8 , cerebellum WM; 9 , cerebellum cortex; 10, cerebellum cortex; 11 , hippocampus; 12 , pallidum; 13, amygdala; 14 , thalamus; 15 , accumbens; 16 , TBV; 17 , cerebral cortex; 18 , putamen.

were just below 0.05 (0.017-0.048). Thus, it seems that sex differences in cortical thickness, even when observed, are statistically small or nonexistent, and that very large samples are necessary to detect them in a reliable way. Since the cortical surface is larger in men, it is likely that cortical volume measures, especially when no corrections for head or brain size are applied, will distinguish more between the sexes than thickness. Group comparisons of volumetry confirmed previous findings of larger brains in men, especially for brainstem, cerebral WM, and cerebral cortex (Courchesne et al., 2000; Goldstein et al., 2001; Ge et al., 2002; Lüders et al., 2002; Raz et al., 2004b; Allen et al., 2005; Luders et al., 2005; Kruggel, 2006; Smith et al., 2007). The effects of sex on ICV-corrected volumes were much smaller, even though men had larger residual volumes of third ventricle, brainstem, cerebellum cortex, thalamus, putamen, pallidum, hippocampus, amygdala, and the cerebral cortex, in addition to TBV. Except for cerebellum cortex ( $3 \%$ explained variance), sex explained between $0.3 \%$ and $1.7 \%$ of the variance in the structures that were significantly different. This supports previous studies showing larger ICV-corrected brain volumes for men (Resnick et al., 2000, 2003; Kruggel, 2006; Chen et al., 2007), but that the differences are small, and only apply to some structures (Blatter et al., 1995; Courchesne et al., 2000; Ge et al., 2002; Gur et al., 2002b; Eberling et al., 2003; Smith et al., 2007; Ikram et al., 2008). Further, as noted by Raz et al. (2004b), corrections for ICV may not be appropriate in testing sex differences in morphometry, as it includes some of the brain variance shared with ICV since the early months of life. The present study also replicated earlier findings that in women's brains the cerebral cortex and the hippocampus occupy a larger part of the TBV than in men's (Filipek et al., 1994; Gur et al., 1999; Goldstein et al., 2001; Lüders et al., 2002; Luders et al., 2005, 2006; Riello et al., 2005; Im et al., 2006; Kruggel, 2006; Chen et al., 2007; Sowell et al., 2007). Men had larger relative volume of brainstem, cerebellum cortex, and pallidum, in addition to all parts of the ventricular system. However, with exception of CSF compartments, all differences were small. Sex explained $\sim 0.6 \%$ of the variance in cortical and $\sim 0.4 \%$ of the variance in hippocampal TBV-corrected volume. Thus, although these effects were statistically significant due to the very large sample, it is unlikely that they have any cognitive implications.

\section{Conclusion}

Previous studies of effects of sex on brain and aging have yielded inconsistent results. In the present cross-sectional study, we

aimed to overcome several sources of discrepancy by basing the analyses on a very large pool of participants from seven different samples. The main finding was that most brain structures were not differentially affected by aging in men and women who were healthy or had Alzheimer's disease. The few observed differences were small and unstable across subsamples. Thus, from the present data, it seems unlikely that men and women differ in the rates of age-related volume loss.

\section{References}

Allen JS, Bruss J, Brown CK, Damasio H (2005) Normal neuroanatomical variation due to age: the major lobes and a parcellation of the temporal region. Neurobiol Aging 26:1245-1260; discussion 1279-1282.

Auer S, Reisberg B (1997) The GDS/FAST staging system. Int Psychogeriatr 9 (Suppl 1):167-171.

Beck AT, Steer RA, Brown GK (1987) Beck depression inventory scoring manual. New York: The Psychological Corporation.

Berg L (1984) Clinical Dementia Rating. Br J Psychiatry 145:339.

Berg L (1988) Clinical Dementia Rating (CDR). Psychopharmacol Bull 24:637-639.

Blatter DD, Bigler ED, Gale SD, Johnson SC, Anderson CV, Burnett BM, Parker N, Kurth S, Horn SD (1995) Quantitative volumetric analysis of brain MR: normative database spanning 5 decades of life. AJNR Am J Neuroradiol 16:241-251.

Blessed G, Tomlinson BE, Roth M (1968) The association between quantitative measures of dementia and of senile change in the cerebral grey matter of elderly subjects. Br J Psychiatry 114:797-811.

Buckner RL, Head D, Parker J, Fotenos AF, Marcus D, Morris JC, Snyder AZ (2004) A unified approach for morphometric and functional data analysis in young, old, and demented adults using automated atlas-based head size normalization: reliability and validation against manual measurement of total intracranial volume. Neuroimage 23:724-738.

Chen X, Sachdev PS, Wen W, Anstey KJ (2007) Sex differences in regional gray matter in healthy individuals aged $44-48$ years: a voxel-based morphometric study. Neuroimage 36:691-699.

Chung SC, Tack GR, Yi JH, Lee B, Choi MH, Lee BY, Lee SY (2006) Effects of gender, age, and body parameters on the ventricular volume of Korean people. Neurosci Lett 395:155-158.

Coffey CE, Lucke JF, Saxton JA, Ratcliff G, Unitas LJ, Billig B, Bryan RN (1998) Sex differences in brain aging: a quantitative magnetic resonance imaging study. Arch Neurol 55:169-179.

Colliot O, Chételat G, Chupin M, Desgranges B, Magnin B, Benali H, Dubois B, Garnero L, Eustache F, Lehéricy S (2008) Discrimination between Alzheimer disease, mild cognitive impairment, and normal aging by using automated segmentation of the hippocampus. Radiology 248:194-201.

Courchesne E, Chisum HJ, Townsend J, Cowles A, Covington J, Egaas B, Harwood M, Hinds S, Press GA (2000) Normal brain development and aging: quantitative analysis at in vivo MR imaging in healthy volunteers. Radiology 216:672-682.

Cowell PE, Turetsky BI, Gur RC, Grossman RI, Shtasel DL, Gur RE (1994) Sex differences in aging of the human frontal and temporal lobes. J Neurosci 14:4748-4755.

Cowell PE, Sluming VA, Wilkinson ID, Cezayirli E, Romanowski CA, Webb JA, Keller SS, Mayes A, Roberts N (2007) Effects of sex and age on regional prefrontal brain volume in two human cohorts. Eur J Neurosci 25:307-318.

Dale AM, Sereno MI (1993) Improved localization of cortical activity by combining EEG and MEG with MRI cortical surface reconstruction: a linear approach. J Cogn Neurosci 5:162-176.

Dale AM, Fischl B, Sereno MI (1999) Cortical surface-based analysis. I. Segmentation and surface reconstruction. Neuroimage 9:179-194.

Du AT, Schuff N, Kramer JH, Rosen HJ, Gorno-Tempini ML, Rankin K, Miller BL, Weiner MW (2007) Different regional patterns of cortical thinning in Alzheimer's disease and frontotemporal dementia. Brain 130:1159-1166. 


\section{Thickness differences females vs. males}

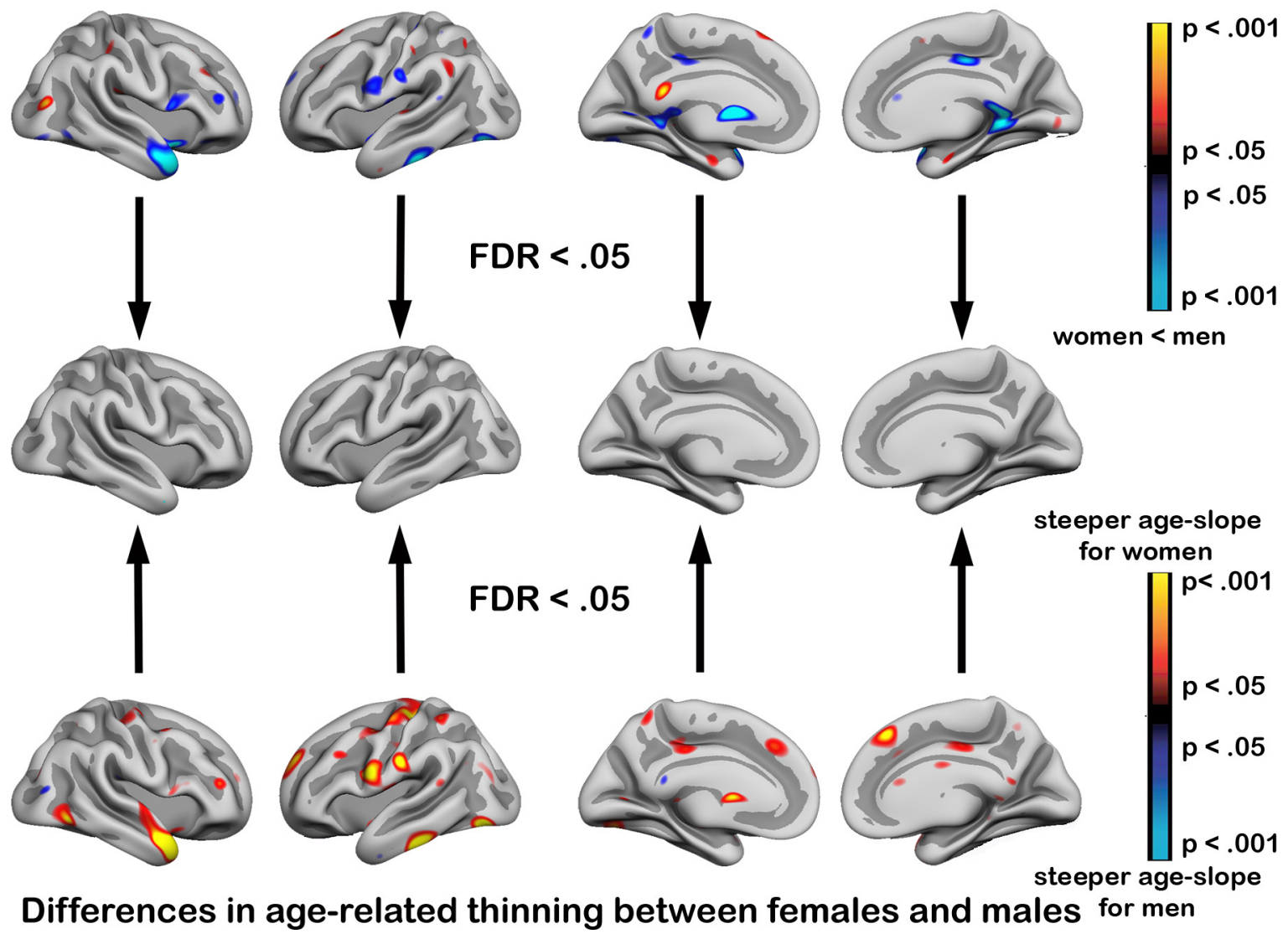

Figure 6. Testing of effects of sex on cortical thickness. The figure shows that no effects of sex on cortical thickness were found when conventional procedures for multiple comparisons (FDR $<$ 0.05 ) were used. Further, there were no significant differences in the age slopes of cortical thickness between women and men when the same threshold was used (FDR $<0.05$ ). Top panel, The effects of sex on cortical thickness are shown as color-coded $p$-value maps, and projected onto a semi-inflated template brain. Blue-green indicates thinner cortex for men than women, while red-yellow indicates that women have thicker cortex ( $p<0.05$, uncorrected). The analyses were corrected for the effects of age and subsample. The middle panel illustrates that all effects vanish if a conventionally used procedure for correction for multiple comparisons is used (FDR $<0.05$ ). Bottom panel, Red-yellow areas indicate that women have more age-related reduction in cortical thickness than men, while blue-green areas indicate the opposite. The analyses are corrected for the effect of subsample. When the results were thresholded at FDR $<0.05$, all effects vanished.

Dubois B, Feldman HH, Jacova C, Dekosky ST, Barberger-Gateau P, Cummings J, Delacourte A, Galasko D, Gauthier S, Jicha G, Meguro K, O’Brien J, Pasquier F, Robert P, Rossor M, Salloway S, Stern Y, Visser PJ, Scheltens P (2007) Research criteria for the diagnosis of Alzheimer's disease: revising the NINCDS-ADRDA criteria. Lancet Neurol 6:734-746.

Eberling JL, Wu C, Haan MN, Mungas D, Buonocore M, Jagust WJ (2003) Preliminary evidence that estrogen protects against age-related hippocampal atrophy. Neurobiol Aging 24:725-732.

Espeseth T, Westlye LT, Fjell AM, Walhovd KB, Rootwelt H, Reinvang I (2008) Accelerated age-related cortical thinning in healthy carriers of apolipoprotein E epsilon 4. Neurobiol Aging 29:329-340.

Filipek PA, Richelme C, Kennedy DN, Caviness VS Jr (1994) The young adult human brain: an MRI-based morphometric analysis. Cereb Cortex 4:344-360.

Fischl B, Dale AM (2000) Measuring the thickness of the human cerebral cortex from magnetic resonance images. Proc Natl Acad Sci U S A 97:11050-11055.

Fischl B, Sereno MI, Dale AM (1999a) Cortical surface-based analysis. II: Inflation, flattening, and a surface-based coordinate system. Neuroimage 9:195-207.

Fischl B, Sereno MI, Tootell RB, Dale AM (1999b) High-resolution intersubject averaging and a coordinate system for the cortical surface. Hum Brain Mapp 8:272-284.

Fischl B, Salat DH, Busa E, Albert M, Dieterich M, Haselgrove C, van der Kouwe A, Killiany R, Kennedy D, Klaveness S, Montillo A, Makris N, Rosen B, Dale AM (2002) Whole brain segmentation: automated labeling of neuroanatomical structures in the human brain. Neuron 33:341-355.
Fischl B, Salat DH, van der Kouwe AJ, Makris N, Ségonne F, Quinn BT, Dale AM (2004) Sequence-independent segmentation of magnetic resonance images. Neuroimage 23 [Suppl 1]:S69-S84.

Fjell AM, Walhovd KB, Amlien I, Bjørnerud A, Reinvang I, Gjerstad L, Cappelen T, Willoch F, Due-Tønnessen P, Grambaite R, Skinningsrud A, Stenset V, Fladby T (2008) Morphometric changes in the episodic memory network and tau pathologic features correlate with memory performance in patients with mild cognitive impairment. AJNR Am J Neuroradiol 29:1183-1189.

Fjell AM, Westlye LT, Amlien I, Espeseth T, Reinvang I, Raz N, Agartz I, Salat D, Greve D, Fischl B, Dale A, Walhovd KB (2009) High consistency of regional cortical thinning in aging across multiple samples. Cereb Cortex. Advance online publication. Retrieved May 28, 2009. doi:10.1093/cercor/bhn232.

Folstein MF, Folstein SE, McHugh PR (1975) "Mini-mental state". A practical method for grading the cognitive state of patients for the clinician. J Psychiatr Res 12:189-198.

Fotenos AF, Snyder AZ, Girton LE, Morris JC, Buckner RL (2005) Normative estimates of cross-sectional and longitudinal brain volume decline in aging and AD. Neurology 64:1032-1039.

Ge Y, Grossman RI, Babb JS, Rabin ML, Mannon LJ, Kolson DL (2002) Age-related total gray matter and white matter changes in normal adult brain. Part I: volumetric MR imaging analysis. AJNR Am J Neuroradiol 23:1327-1333.

Goldstein JM, Seidman LJ, Horton NJ, Makris N, Kennedy DN, Caviness VS Jr, Faraone SV, Tsuang MT (2001) Normal sexual dimorphism of the adult human brain assessed by in vivo magnetic resonance imaging. Cereb Cortex 11:490-497. 
Good CD, Johnsrude IS, Ashburner J, Henson RN, Friston KJ, Frackowiak RS (2001) A voxel-based morphometric study of ageing in 465 normal adult human brains. Neuroimage 14:21-36.

Greenberg DL, Messer DF, Payne ME, Macfall JR, Provenzale JM, Steffens DC, Krishnan RR (2008) Aging, gender, and the elderly adult brain: an examination of analytical strategies. Neurobiol Aging 29:290-302.

Gunning-Dixon FM, Head D, McQuain J, Acker JD, Raz N (1998) Differential aging of the human striatum: a prospective MR imaging study. AJNR Am J Neuroradiol 19:1501-1507.

Gur RC, Turetsky BI, Matsui M, Yan M, Bilker W, Hughett P, Gur RE (1999) Sex differences in brain gray and white matter in healthy young adults: correlations with cognitive performance. J Neurosci 19:4065-4072.

Gur RC, Gunning-Dixon FM, Turetsky BI, Bilker WB, Gur RE (2002a) Brain region and sex differences in age association with brain volume: a quantitative MRI study of healthy young adults. Am J Geriatr Psychiatry 10:72-80.

Gur RC, Gunning-Dixon F, Bilker WB, Gur RE (2002b) Sex differences in temporo-limbic and frontal brain volumes of healthy adults. Cereb Cortex 12:998-1003.

Halpern DF, Tan U (2001) Stereotypes and steroids: using a psychobiosocial model to understand cognitive sex differences. Brain Cogn 45:392-414.

Han X, Fischl B (2007) Atlas renormalization for improved brain MR image segmentation across scanner platforms. IEEE Trans Med Imaging 26:479-486.

Han X, Jovicich J, Salat D, van der Kouwe A, Quinn B, Czanner S, Busa E, Pacheco J, Albert M, Killiany R, Maguire P, Rosas D, Makris N, Dale A, Dickerson B, Fischl B (2006) Reliability of MRI-derived measurements of human cerebral cortical thickness: the effects of field strength, scanner upgrade and manufacturer. Neuroimage 32:180-194.

Ikram MA, Vrooman HA, Vernooij MW, van der Lijn F, Hofman A, van der Lugt A, Niessen WJ, Breteler MM (2008) Brain tissue volumes in the general elderly population. The Rotterdam Scan Study. Neurobiol Aging 29:882-890.

Im K, Lee JM, Lee J, Shin YW, Kim IY, Kwon JS, Kim SI (2006) Gender difference analysis of cortical thickness in healthy young adults with surface-based methods. Neuroimage 31:31-38.

Jernigan TL, Archibald SL, Fennema-Notestine C, Gamst AC, Stout JC, Bonner J, Hesselink JR (2001) Effects of age on tissues and regions of the cerebrum and cerebellum. Neurobiol Aging 22:581-594.

Jones CM, Braithwaite VA, Healy SD (2003) The evolution of sex differences in spatial ability. Behav Neurosci 117:403-411.

Kruggel F (2006) MRI-based volumetry of head compartments: normative values of healthy adults. Neuroimage 30:1-11.

Kuperberg GR, Broome MR, McGuire PK, David AS, Eddy M, Ozawa F, Goff D, West WC, Williams SC, van der Kouwe AJ, Salat DH, Dale AM, Fischl B (2003) Regionally localized thinning of the cerebral cortex in schizophrenia. Arch Gen Psychiatry 60:878-888.

Lemaître H, Crivello F, Grassiot B, Alpérovitch A, Tzourio C, Mazoyer B (2005) Age- and sex-related effects on the neuroanatomy of healthy elderly. Neuroimage 26:900-911.

Lüders E, Steinmetz H, Jäncke L (2002) Brain size and grey matter volume in the healthy human brain. Neuroreport 13:2371-2374.

Luders E, Narr KL, Thompson PM, Woods RP, Rex DE, Jancke L, Steinmetz $\mathrm{H}$, Toga AW (2005) Mapping cortical gray matter in the young adult brain: effects of gender. Neuroimage 26:493-501.

Luders E, Narr KL, Thompson PM, Rex DE, Woods RP, Deluca H, Jancke L, Toga AW (2006) Gender effects on cortical thickness and the influence of scaling. Hum Brain Mapp 27:314-324.

Marcus DS, Wang TH, Parker J, Csernansky JG, Morris JC, Buckner RL (2007) Open Access Series of Imaging Studies (OASIS): cross-sectional MRI data in young, middle aged, nondemented, and demented older adults. J Cogn Neurosci 19:1498-1507.

Morris JC (1993) The Clinical Dementia Rating (CDR): current version and scoring rules. Neurology 43:2412-2414.

Morris JC, Storandt M, Miller JP, McKeel DW, Price JL, Rubin EH, Berg L (2001) Mild cognitive impairment represents early-stage Alzheimer disease. Arch Neurol 58:397-405.

Murphy DG, DeCarli C, McIntosh AR, Daly E, Mentis MJ, Pietrini P, Szczepanik J, Schapiro MB, Grady CL, Horwitz B, Rapoport SI (1996) Sex differences in human brain morphometry and metabolism: an in vivo quantitative magnetic resonance imaging and positron emission tomography study on the effect of aging. Arch Gen Psychiatry 53:585-594.

Nesvåg R, Lawyer G, Varnäs K, Fjell AM, Walhovd KB, Frigessi A, Jönsson EG, Agartz I (2008) Regional thinning of the cerebral cortex in schizophrenia: effects of diagnosis, age and antipsychotic medication. Schizophr Res 98:16-28.

Nunnemann S, Wohlschläger AM, Ilg R, Gaser C, Etgen T, Conrad B, Zimmer C, Mühlau M (2009) Accelerated aging of the putamen in men but not in women. Neurobiol Aging 30:147-151.

Pruessner JC, Collins DL, Pruessner M, Evans AC (2001) Age and gender predict volume decline in the anterior and posterior hippocampus in early adulthood. J Neurosci 21:194-200.

Raz N, Gunning FM, Head D, Dupuis JH, McQuain J, Briggs SD, Loken WJ, Thornton AE, Acker JD (1997) Selective aging of the human cerebral cortex observed in vivo: differential vulnerability of the prefrontal gray matter. Cereb Cortex 7:268-282.

Raz N, Rodrigue KM, Head D, Kennedy KM, Acker JD (2004a) Differential aging of the medial temporal lobe: a study of a five-year change. Neurology 62:433-438.

Raz N, Gunning-Dixon F, Head D, Rodrigue KM, Williamson A, Acker JD (2004b) Aging, sexual dimorphism, and hemispheric asymmetry of the cerebral cortex: replicability of regional differences in volume. Neurobiol Aging 25:377-396.

Raz N, Rodrigue KM, Haacke EM (2007) Brain aging and its modifiers: insights from in vivo neuromorphometry and susceptibility weighted imaging. Ann N Y Acad Sci 1097:84-93.

Resnick SM, Goldszal AF, Davatzikos C, Golski S, Kraut MA, Metter EJ, Bryan $\mathrm{RN}$, Zonderman AB (2000) One-year age changes in MRI brain volumes in older adults. Cereb Cortex 10:464-472.

Resnick SM, Pham DL, Kraut MA, Zonderman AB, Davatzikos C (2003) Longitudinal magnetic resonance imaging studies of older adults: a shrinking brain. J Neurosci 23:3295-3301.

Riello R, Sabattoli F, Beltramello A, Bonetti M, Bono G, Falini A, Magnani G, Minonzio G, Piovan E, Alaimo G, Ettori M, Galluzzi S, Locatelli E, Noiszewska M, Testa C, Frisoni GB (2005) Brain volumes in healthy adults aged 40 years and over: a voxel-based morphometry study. Aging Clin Exp Res 17:329-336.

Rosas HD, Liu AK, Hersch S, Glessner M, Ferrante RJ, Salat DH, van der Kouwe A, Jenkins BG, Dale AM, Fischl B (2002) Regional and progressive thinning of the cortical ribbon in Huntington's disease. Neurology 58:695-701.

Salat DH, Buckner RL, Snyder AZ, Greve DN, Desikan RS, Busa E, Morris JC, Dale AM, Fischl B (2004) Thinning of the cerebral cortex in aging. Cereb Cortex 14:721-730.

Smith CD, Chebrolu H, Wekstein DR, Schmitt FA, Markesbery WR (2007) Age and gender effects on human brain anatomy: a voxel-based morphometric study in healthy elderly. Neurobiol Aging 28:1075-1087.

Sowell ER, Peterson BS, Kan E, Woods RP, Yoshii J, Bansal R, Xu D, Zhu H, Thompson PM, Toga AW (2007) Sex differences in cortical thickness mapped in 176 healthy individuals between 7 and 87 years of age. Cereb Cortex 17:1550-1560.

Walhovd KB, Fjell AM, Reinvang I, Lundervold A, Dale AM, Eilertsen DE, Quinn BT, Salat D, Makris N, Fischl B (2005a) Effects of age on volumes of cortex, white matter and subcortical structures. Neurobiol Aging 26: 1261-1270; discussion 1275-1278.

Walhovd KB, Fjell AM, Reinvang I, Lundervold A, Dale AM, Quinn BT, Salat D, Makris N, Fischl B (2005b) Neuroanatomical aging: universal but not uniform. Neurobiol Aging 26:1279-1283.

Walhovd KB, Moe V, Slinning K, Due-Tønnessen P, Bjørnerud A, Dale AM, van der Kouwe A, Quinn BT, Kosofsky B, Greve D, Fischl B (2007) Volumetric cerebral characteristics of children exposed to opiates and other substances in utero. Neuroimage 36:1331-1344.

Wechsler D (1999) Wechsler abbreviated scale of intelligence. San Antonio, TX: The Psychological Corporation.

Xu J, Kobayashi S, Yamaguchi S, Iijima K, Okada K, Yamashita K (2000) Gender effects on age-related changes in brain structure. AJNR Am J Neuroradiol 21:112-118. 